\title{
ANALISIS ELEMEN VISUAL PADA PROMOSI BUSANA MUSLIMAH DI INSTAGRAM (Studi Kasus Merek Hijab Juniper Lane, Zaha, dan Zysku Xena di Bandung)
}

\author{
Ramadita Fetrianggi', Intan Rizky Mutiaz ${ }^{2}$, Dian Widiawati ${ }^{3}$ \\ 1,2,3 Fakultas Seni Rupa dan Desain Institut Teknologi Bandung \\ Jl. Ganesha No. 10 Bandung \\ E-mail: ramaditafetrianggi@gmail.com
}

\begin{abstract}
Analysis of Visual Elements on Muslimah Clothing Promotion in Instagram (Case Study on Brands of Hijab Juniper Lane, Zaha, and Zysku Xena in Bandung). Muslim clothing in the form of hijab has become popular as a religious lifestyle and identity. The popularity of hijab is due to the promotion of marketing through instagram displaying muslim fashion clothing that is designed very interesting, so that consumers become interested and marketing becomes increasing. This study aims to examine muslim clothing photos on instagram hijab with brands of Juniper Lane, Zaha, and Zysku Xena in Bandung seen from the visual elements of photography. The research method used case study with descriptive approach through visual analysis. The research subjects are instagram photos on Juniper Lane hijab brand, Zaha, and Zysku Xena in Bandung. Data collection techniques were collected by observation, instagram photo documentation study, and interviews with local brand owners of hijab and consumers. Data were analyzed by visual analysis, content analysis, and qualitative analysis. The results show that muslim clothing photos on instagram with brands of hijab Juniper Lane, Zaha, and Zysku Xena in Bandung have fulfilled the visual elements of photography, so the photo design becomes attractive, the consumers become interested in them, and the marketing becomes increasing.
\end{abstract}

Keywords: hijab; visual element; instagram.

\begin{abstract}
Abstrak: Analisis Elemen Visual Pada Promosi Busana Muslimah di Instagram (Studi Kasus: Merek Hijab Juniper Lane, Zaha, dan Zysku Xena di Bandung). Busana muslimah dalam bentuk hijab kini menjadi populer sebagai gaya hidup dan identitas diri yang religius. Kepopuleran hijab tersebut salah satunya berkat promosi pemasaran melalui instagram yang memajang foto busana muslimah yang didesain amat menarik, sehingga konsumen menjadi tertarik dan pemasaran menjadi meningkat. Penelitian ini bertujuan untuk mengkaji foto busana muslimah pada instagram merek hijab Juniper Lane, Zaha, dan Zysku Xena di Bandung dilihat dari elemen visual fotografi. Metode penelitian menggunakan studi kasus dengan pendekatan deskriptif melalui analisis visual. Subyek penelitian yaitu foto instagram pada merek hijab Juniper Lane, Zaha, dan Zysku Xena di Bandung. Teknik pengumpulan data dihimpun dengan observasi, studi dokumentasi foto instagram, dan wawancara dengan pemilik merek lokal hijab dan konsumen. Data dianalisis dengan teknik analisis visual, analisis konten, dan analisis kualitatif. Hasil penelitian menunjukkan bahwa foto busana muslimah pada instagram pemasaran merek hijab Juniper Lane, Zaha, dan Zysku Xena di Bandung telah memenuhi elemen visual fotografi, sehingga desain fotonya menjadi menarik, konsumen menjadi menyukai, dan pemasarannya menjadi meningkat.
\end{abstract}

Kata kunci: hijab; elemen visual; instagram.

\section{Pendahuluan}

Busana muslimah merupakan pakaian yang digunakan kaum wanita yang sesuai dengan ajaran agama Islam. Busana muslimah ini disebut juga dengan istilah hijab. Di Indonesia sebagaimana dikutip dari muslimmarket.com', busana hijab kini

'Agnessia P. Larasati, Hijab Syari vs Hijab Gaul, Fenomena Hijab Masa Kini. https://www.muslimarket.com/blog/hijab-syari-vs- sedang popular dan mengalami perkembangan yang cukup pesat. Setiap wanita muslim hampir seluruhnya mengenakan busana muslimah dengan berbagai mode. Sesungguhnya mode busana muslimah ini ada etika atau kriterianya. Kriteria busana muslimah menurut Syeikh Muhammad Nashiruddin al-Albani dan Majelis Ulama Indonesia

hijab-gaul-fenomena-hijab-masa-kini, diakses tanggal 30 Mei 2016. 
(MUI) dalam Sukendro² diantaranya (1) pakaian harus menutupi seluruh tubuh, selain yang dikecualikan yaitu wajah dan telapak tangan, (2) hendaknya pakaian tidak berwarna-warni yang mencolok (sebagai perhiasan) sehingga dapat memancing perhatian lawan jenis, (3) bahan pakaian harus tebal, tidak tipis dan transparan sehingga permukaan kulit benar-benar tertutup rapat, (4) bentuk pakaian harus longgar, tidak ketat sehingga tidak menampakkan lekukan tubuh, (5) hendaknya pakaian tidak diberi wewangian atau parfum, (6) bentuk pakaian tidak menyerupai lawan jenis, (7) desain pakaian tidak menyerupai pakaian perempuan yang tidak beriman atau non muslim, dan (8) hendaknya pakaian tidak dimaksudkan untuk memperoleh popularitas.

Busana muslimah atau hijab terdiri atas kerudung (khimar) dan jilbab (pakaian luar). Perintah memakai busana muslimah dalam ajaran Islam telah difirmankan Allah Swt dalam surat alAhzâb [33]: 59 yang memerintahkan agar wanita mengulurkan jilbabnya ke seluruh tubuhnya dan dalam surat An-Nûr [24]: 31 agar menutupi dadanya dengan memanjangkan kain kerudung. Busana muslimah digunakan bukan hanya sebagai penutup aurat saja, akan tetapi juga berfungsi untuk menjaga kehormatan, mudah dikenal, dan melindungi kaum wanita itu sendiri.

Di lapangan, masih banyak dijumpai kaum wanita muslimah yang memakai busana tidak sesuai dengan kaidah ajaran Islam. Mereka memakai busana dengan standar asal kepalanya berkerudung saja. Melalui standar ini muncul berbagai model jilbab dari yang panjang hingga lutut, sedada, atau bahkan hanya sampai leher dengan beragam warna dan motif yang menarik. Bahkan terdapat istilah "jilbab gaul” yang bermakna bahwa penggunanya mengenakan jilbab hanya sampai batas leher dan ini banyak dipakai oleh para remaja, mahasiswa bahkan ibu-ibu yang ingin tampil modis dan trendi. Busana muslimah yang dahulu dianggap kuno dan tardisional, kini berkembang menjadi gaya hidup yang tak terpisahkan dari wanita modern. Hijab di masa

${ }^{2}$ Gatot Sukendro, Nilai Fetisisme Komoditi Gaya Hijab (Kerudung dan Jilbab) dalam Busana Muslimah, (Bandung: Tesis S2 Prodi Desain, 2015). kini mengalami perkembangan yang pesat, baik dari segi pakaian, model, aksesoris, maupun kreasi fashion-nya.

Popularitas hijab di tahun 2010-an disebabkan beberapa faktor yang salah satunya turut menyumbangkan adalah berkat penggunaan media online. Melalui media ini baik penjual maupun konsumen amat dimanjakan dengan berbagai fasilitas layanan. Bagi penjual dapat mempromosikan produk hijab yang dijual kepada calon konsumen melalui media instagram. Instagram ini berisikan berbagai foto-foto hijab lengkap dengan desain, model, dan informasi yang amat menarik serta dapat dilihat secara praktis oleh calon konsumen kapan saja dan di mana saja. Calon konsumen tidak perlu repot lagi mendatangi alamat toko dengan menggunakan transportasi mahal, tenaga yang banyak, dan waktu yang lama. Dengan hanya menggunakan smartphone, calon konsumen kini dapat langsung membeli produk hijab yang disukainya.

Penduduk muslim terbanyak di dunia yaitu Indonesia. Penduduk muslim di Indonesia menurut situs marketing.co.id ${ }^{3}$, berjumlah 199 juta orang atau $85,2 \%$ dari seluruh penduduk. Kekayaan jumlah penduduk muslim yang banyak dan antusias wanita dalam mengenakan hijab, memberikan harapan bagi Indonesia untuk menjadi pasar dan kiblat fashion muslim di dunia. Dalam kompasiana.com ${ }^{4}$, desainer Ria Miranda menjelaskan bahwa kontribusi terbesar dalam mewujudkan impian sebagai pasar dunia yaitu berkat dukungan dari para hijaber Indonesia. Para konsumen hijab memberikan dukungan dalam bentuk seperti tetap percaya diri dan terus memakai hijab, serta bangga menggunakan merek hijab produk dalam negeri. Berbagai desainer dan merek-merek hijab telah muncul dan sukses memicu para pelaku bisnis menciptakan merekmerek lokal hijab lainnya.

Pelopor hijab di Indonesia seperti desainer Dian Pelangi, Ria Miranda, Jenahara, dan Zaskia

${ }^{3}$ Cecep Supriadi, Pasar Muslim Indonesia yang Menggiurkan. http://www.marketing.co.id/pasar-muslim-indonesia-yangmenggiurkan, diakses tanggal 23 Februari 2016.

${ }^{4}$ Fifi Kusuma, Hijab dan Perempuan Indonesia. http://www. kompasiana.com/fifikusuma/hijab-dan-perempuan-indonesia_5 4f681bfa3331184118b4dd2, diakses tanggal 23 Februari 2016. 
Sungkar telah memproduksi hijab dengan karakteristik desain khusus sehingga menarik konsumen. Dian Pelangi lebih fokus menggunakan warna-warna yang sesuai dengan namanya yaitu pelangi, Ria Miranda dengan memilih warnawarna pastel pada desainnya, Jenahara dengan tema urban wear yang cocok bagi muslimah berjiwa muda, dan Zaskia Sungkar memilih ciri khas yang sesuai dengan dirinya yaitu simpel dan elegan. Kesuksesan produk hijab mereka disusul munculnya merek lain seperti Rabbani, Elzatta, Zoya, dan Shafira yang merupakan beberapa nama merek hijab yang sudah terkenal dan memiliki cabang tersebar hampir di seluruh Indonesia. Mereka kini tidak hanya mengandalkan toko fisik saja, melainkan juga memasarkan produknya melalui website resmi mereka. Setiap merek hijab ini memiliki ciri khas tersendiri dalam desain hijabnya seperti ada yang fokus ke penampilan casual, formal, simpel hingga yang paling rumit. Demikian pula kini telah bermunculan merekmerek lokal seperti Juniper Lane, Hijab Princess, Ethniq Couture, Maima, dan sebagainya; yang turut meramaikan pasar busana muslim di Indonesia.

Merek produk hijab yang kini terkenal pada awalnya hanyalah merek kecil yang kurang bonafit. Mereka memiliki toko fisik yang kecil dengan memajang produk hijab seadanya saja. Namun karena kegigihan beberapa merekmerek lokal tersebut mulai dikenal dan banyak peminatnya. Upaya mereka dalam memasarkan produk kini tidak hanya mengandalkan sebatas toko fisik yang dimiliki, namun seiring dengan kemajuan teknologi mereka telah menggunakan media online untuk memasarkan produk. Melalui pemanfaatan internet, kini nama merek-merek lokal tersebut digandrungi para hijaber Indonesia mulai dari muda sampai tua 5 .

Setiap merek-merek lokal memiliki strategi pemasaran dan promosinya masing-masing untuk menarik minat beli calon konsumen. Konsumen pun seolah dihipnotis agar selalu memilih dan menanti produk-produk mereka. Mereka tahu

5 Jawa Pos, Andalkan Distinctive Stsssyle, Digandrungi Pasar Australia. http://beta.tirto.id/20160314-media-cetak/andalkandistinctive-style-digandrungi-pasar-australia-55167, diakses tanggal 27 Mei 2016. benar bahwa strategi dalam pemasaran dan promosinya didesain melalui tampilan visual dari produk hijab itu sendiri, sehingga mampu menghipnotis konsumen untuk membelinya. Pendekatan visual yang disajikan tiap merekmerek lokal ini memiliki perbedaan dan ciri khasnya masing-masing. Mereka mendesain tampilan foto hijab yang dijual dari berbagai susut pandang hingga penggunaan model wanita yang memperagakan agar memiliki kekhasan tersendiri yang secara tidak langsung mempengaruhi dalam menarik perhatian para konsumen.

Di era digital pemasaran produk lebih mengutamakan daya tarik visual ${ }^{6}$. Daya tarik visual merupakan faktor penentu bagi promosi dalam pemasaran. Suatu produk busana muslimah yang kurang begitu menarik, namun karena didesain visualnya bagus; maka menjadi booming dan laku keras. Sebaliknya produk suatu merek yang memiliki mutu bagus, namun karena desain visualnya kurang memperhatikan daya tarik promosi; maka menjadi tidak laku dan merugi. Faktor kemenarikan visual inilah menjadi salah satu strategi dalam pemasaran suatu produk.

Di Bandung terdapat beberapa produsen hijab yang terkenal, seperti merek Juniper Lane, Zaha, dan Zysku Xena. Berdasarkan pengamatan dan wawancara pendahuluan, ketiga merek lokal hijab ini merupakan merek hijab yang cukup favorit dan memiliki omset penjualan yang besar. Merekmerek ini memfokuskan pemasaran produknya melalui media instagram dan telah memiliki 30-80 ribu followers. Disamping hal tersebut, ketiga merek hijab ini mempunyai kiat khusus yaitu dengan memposting foto pada instagram yang menarik dan selalu di update secara rutin agar para konsumen melirik produknya. Dalam sehari merek-merek ini dapat memposting foto sekitar 2-3 kali pada waktu-waktu prime time dan berusaha memvariasikan konten-konten postingan tidak monoton foto produk saja, tetapi diselingi dengan foto-foto yang berhubungan dengan brand seperti foto konsumen memakai produk atau event-event tertentu.

\footnotetext{
${ }^{6}$ Smart Bisnis, Peran Design Visual dalam Pemasaran Produk. http://www.smartbisnis.co.id/content/read/belajar-bisnis/inisiasibisnis/peran-design-visual-dalam-pemasaran-produk, diakses tanggal 16 September 2016.
} 
Berdasarkan fenomena sebagaimana telah dipaparkan, peneliti merasa tertarik untuk mendalami secara lebih lanjut melalui penelitian dengan menggunakan studi kasus. Hal ini didasarkan kepada beberapa pertimbangan. Pertama, busana muslimah atau hijab merupakan busana yang sedang popular sebagai identitas masyarakat religius. Kedua, produsen hijab merek Juniper Lane, Zaha, dan Zysku Xena di Bandung merupakan merek yang sukses dalam pemasaran, cukup favorit bagi konsumen, memasarkan melalui media instagram dengan memajang foto busana muslimah, dan banyak pelanggannya. Ketiga, foto busana muslimah pada instagram sebagai promosi pemasaran merek hijab belum pernah diteliti dan dikaji dari elemen visual, serta sejauh mana persepsi konsumen terhadap elemen visual fotografi pada promosi instagram ketiga merek lokal hijab di Bandung. Hal ini amat penting dikaji sebagai feedback (umpan balik) bagi produsen dalam mendesain foto instagram, sehingga dapat berkontribusi bagi peningkatan pemasaran.

Penelitian ini memaparkan bagaimana foto busana muslimah pada instagram merek Juniper Lane, Zaha, dan Zysku Xena di Bandung dikaji dari elemen visual fotografi. Selanjutnya secara khusus memaparkan bagaimana elemen visual fotografi dimanfaatkan untuk memperkuat strategi promosi pada instagram, dan persepsi konsumen terhadap elemen visualisasi promosi merek-merek hijab di Bandung tersebut.

Tujuan umum penelitian ini yaitu untuk menganalisis foto busana muslimah pada instagram merek Juniper Lane, Zaha, dan Zysku Xena di Bandung dikaji dari elemen visual fotografi. Tujuan umum tersebut selanjutnya dibagi menjadi tujuan khusus, yaitu (1) untuk menganalisis elemen visual fotografi dimanfaatkan untuk memperkuat strategi promosi pada instagram; dan (2) untuk menganalisis persepsi konsumen terhadap elemen visualisasi promosi merek hijab di Bandung tersebut.

Tujuan tersebut secara khusus untuk (1) menganalisis elemen visual fotografi yang dapat memperkuat strategi promosi pada Instagram sesuai, dan (2) menganalisis persepsi konsumen terhadap elemen visualisasi promosi merek hijab di Bandung. Kedua tujuan penelitian ini digunakan untuk melihat strategi promosi merek dagang busana muslimah di Bandung dari segi teori promosi dalam ilmu ekonomi Islam. Seperti dalam teori promosi ilmu ekonomi Islam perlu menjunjung syariah sesuai Alquran surat alJâtsiyah [45]: 18, menunjung tinggi akhlak "AlAmin" Rasulullah Saw dalam berbisnis ${ }^{7}$, dan sesuai nilai spiritual marketing ${ }^{8}$. Melalui kedua analisis ini akan memperkuat teori promosi dalam perspektif ilmu ekonomi Islam.

Penelitian ini mempunyai manfaat teoritis dan praktis. Manfaat teoritis yaitu melalui penelitian ini diharapkan dapat memberikan wawasan tentang kajian visualisasi pada foto busana muslimah merek hijab Juniper Lane, Zaha, dan Zysku Xena di Bandung. Analisis ini bermanfaat bagi pengembangan dan sumbangan keilmuan dalam bidang ilmu desain dan penelitian lebih lanjut. Manfaat praktis yang dapat diperoleh dari hasil penelitian ini yaitu dapat dijadikan sebagai acuan dalam mempromosikan produk melalui pemanfaatan elemen visual fotografi yang sesuai dengan kode etik marketing dalam ekonomi Islam seperti teistis (rabbâniyyah) atau sesuai dengan ketentuan Allah Swt, etis (akhlâqiyyah) atau bermoral baik, realistis (al-wâqiyyah) atau profesional, dan humanistis (insâniyyah) atau menjunjung tinggi nilai kemanusiaan`. Selain itu, penelitian ini juga dapat bermanfaat untuk memperbaiki desain promosi dan produksi busana muslimah guna mewujudkan impian Indonesia menjadi kiblat fashion muslim dunia.

\section{Metodologi}

Penelitian ini menggunakan metode studi kasus. Metode ini digunakan dengan maksud untuk mempelajari secara lebih khusus dan mendalam tentang foto busana muslimah pada promosi Instagram merek hijab Juniper Lane, Zaha, dan Zysku Xena di Bandung. Pendekatan yang digunakan dengan deskriptif kualitatif

${ }^{7}$ Idris Parakkasi, MarketingSyariah, http://konsultanekonomi. blogspot.co.id/2012/05/marketing-syariah.html, diakses tanggal 22 Mei 2017.

${ }^{8}$ Stephen R. Covey, The 7 Habits of Highly Effective People, (Jakarta: Binarupa Aksara, 1997), h. 190-192

9 Muhammad Sula dan Hermawan Kartajaya, Syariah Marketing, (Jakarta: Mizan, 2005), h. 28-39 
melalui analisis konten ${ }^{10}$. Pendekatan deskriptif kualitatif merupakan suatu studi yang berupaya menjelaskan suatu fenomena atau variabel secara deskripsi dengan narasi yang jelas. Pendekatan analisis konten yaitu gambaran sistematis dari bentuk dan konten tulisan, ucapan, atau materi visual yang disajikan dalam tema, pola, dan menghitung kejadian dari kata-kata, frase, gambar, atau konsep ${ }^{11}$.

Subyek atau sampel penelitian ini difokuskan pada foto busana muslimah atau hijab merek Juniper Lane, Zaha, dan Zysku Xena di Bandung. Pemilihan subyek ini didasarkan kepada pertimbangan bahwa ketiga merek lokal di Bandung ini merupakan produsen hijab yang menfokuskan pemasaran melalui media online instagram, paling favorit bagi pelanggan, mempunyai jumlah followers instagram yang banyak, dan omset penjualan yang tinggi. Adapun responden dalam penelitian ini yaitu pemilik dan 30 konsumen pengguna merek lokal hijab di Bandung.

Teknik pengumpulan data dalam penelitian ini dilakukan dengan cara observasi, wawancara, studi dokumentasi, dan studi pustaka. Observasi dilakukan melalui proses pengamatan dan pencatatan mengenai pola aktivitas komunikasi pada media online instagram dari merek Juniper Lane, Zaha, dan Zysku Xena di Bandung. Wawancara dilakukan dengan cara bertanya langsung dengan pemilik dan konsumen ketiga merek lokal hijab di Bandung. Studi dokumentasi dilakukan dengan mempelajari data-data terkait langsung dan tidak langsung terhadap subyek penelitian. Studi pustaka dilakukan dengan mengumpulkan informasi yang relevan dari berbagai buku, jurnal, makalah, artikel ilmiah, situs web, surat kabar yang berhubungan dengan topik penelitian.

Analisis data dilakukan dengan teknik analisis konten pada foto promosi instagram busana muslimah merek Juniper Lane, Zaha, dan Zysku Xena dikaji dari segi elemen visual fotografi' ${ }^{12}$.

\footnotetext{
${ }^{10}$ Sugiyono, Memahami Penelitian Kualitatif, (Bandung: Alfabeta, 2012), h. 1

1 Martin, B. dan Hanington, B., Universal Methods of Design: 100 Ways to Research Complex Problems, Develop Innovative Ideas, and Design Effective Solutions, (Beverly: Rockport Publishers, 2012), h. 40

${ }_{12}$ Didit W. Soewardikoen, Metodologi Penelitian Visual dari Seminar ke Tugas Akhir, (Bandung: CV Dinamika Komunika,
}

Kajian elemen visual dengan menggunakan analisis visual fotografi dilihat dari elemen tonal warna, jenis pengambilan gambar, arah pandang kamera, objek foto, latar, dan komposisi serta gaya busana yang dikaji dari aksesori dan atribut busana. Demikian pula data yang dihimpun melalui wawancara dianalisis secara kualitatif dengan langkah pengumpulan data, reduksi data, pemaparan, verifikasi, dan simpulan yang dilakukan secara berulang-ulang ${ }^{13}$.

\section{Hasil dan Pembahasan}

\section{Analisis Konten Terhadap Promosi Instagram Merek Juniper Lane, Zaha, dan Zysku Xena}

Foto pada instagram dari merek Juniper Lane, Zaha, dan Zysku Xena dikategorikan berdasarkan observasi secara langsung pada media online tersebut yang diambil dari kurun waktu 2015-2016. Pengkategorian didasari dari frekuensi unsur visual yang sering muncul pada foto-foto instagram masing-masing merek lokal hijab tersebut. Berikut ketegori yang didapat dari setiap merek lokal hijab di Bandung.

Foto pada akun instagram Juniper Lane terdapat 512 post dan memiliki 16 jenis kategori. Kategori foto tersebut diantaranya ialah (1) konsumen memakai produk, (2) toko fisik, (3) penjelasan customer service, website, reseller, (4) repost foto bazar kolaborasi, fashion show kolaborasi, dll., (5) kegiatan di luar penjualan (fashion show, wawancara, dll.), (6) booth bazar dan suasananya, (7) behind the scene photoshot, (8) keterangan sale produk, (9) produk (foto single), (10) produk (foto gabungan), (11) repost foto kolaborasi toko dengan merek lain, (12) ucapan seperti untuk lebaran, 17 Agustusan, dll., (13) owner yang memakai produk sendiri, (14) produk dipakai selebriti/selebgram, (15) produk pakaian yang sedang digantung di toko, dan (16) suasana toko saat sale.

Zaha memiliki jumlah foto pada instagramnya sebanyak 928 post dan terdapat 20 jenis kategori foto. Kategori foto tersebut yaitu (1) produk (foto single), (2) produk (foto gabungan), (3) keterangan sale produk, (4) booth bazar dan

\footnotetext{
2013), h. 35

13 Sugiyono, Memahami Penelitian Kualitatif, (Bandung: Alfabeta, 2012), h. 89
} 
suasananya, (5) kegiatan di luar penjualan (fashion show, wawancara, dll.), (6) konsumen memakai produk, (7) repost foto bazar kolaborasi, fashion show kolaborasi, dll., (8) produk dipakai selebriti/ selebgram, (9) ucapan seperti untuk lebaran, belasungkawa, dll., (10) owner berfoto dengan selebriti/selebgram yang berbelanja produk, (11) produk pakaian yang sedang digantung di toko, (12) behind the scene photoshot, (13) repost foto kolaborasi toko dengan merek lain, (14) quotes, (15) repost foto bazar kolaborasi, fashion show kolaborasi, dll., (16) konsumen yang sedang/ selesai berbelanja, (17) mengadakan kompetisi, (18) suasana toko saat sale, (19) penjelasan customer service, website, reseller, dan (20) toko fisik.

Media sosial Instagram Zysku Xena saat ini telah memiliki foto sebanyak 1.727 post dan memiliki 18 jenis kategori. Kategori foto pada instagram Zysku Xena adalah (1) konsumen memakai produk, (2) produk (foto single), (3) produk (foto gabungan), (4) penjelasan customer service, website, reseller, (5) produk dipakai selebriti/selebgram, (6) owner berfoto dengan selebriti/selebgram yang berbelanja produk, (7) booth bazar dan suasananya, (8) produk pakaian yang sedang digantung di toko, (9) quotes, (10) kegiatan di luar penjualan (fashion show, wawancara, dll.), (11) owner yang memakai produk sendiri, (12) ucapan seperti untuk lebaran, belasungkawa, dll., (13) keterangan sale produk, (14) owner yang memakai produk sendiri, (15) keterangan kolaborasi toko dengan merek lain, (16) toko fisik, (17) behind the scene photoshot, dan (18) suasana toko saat sale.

Dari pengkategorian pada masing-masing instagram merek Juniper Lane, Zaha, dan Zysku Xena di atas dapat ditarik kesamaan unsur satu sama lain dan dilihat frekuensi keseringan munculnya unsur. Terdapat enam kategori foto yang memiliki kesamaan unsur yaitu (1) produk (foto single), (2) produk (foto gabungan), (3) produk dipakai selebriti/selebgram, (4) konsumen memakai produk, (5) kegiatan penjualan offline, dan (6) kegiatan di luar penjualan (fashion show). Kategori ini merupakan foto terbanyak pada instagram ketiga merek hijab di Bandung tersebut. Terdapat juga kesamaan kategori diluar enam jenis foto, tetapi frekuensi kemunculannya sangat jarang dan kurangnya jumlah foto yang akan dianalisis visual selanjutnya, sehingga tidak dapat dijadikan kategorisasi.

\section{Analisis Visual Terhadap Promosi Instagram Merek Juniper Lane, Zaha, dan Zysku Xena}

Pada penelitian ini, analisis visual dilakukan berdasarkan teori umum mengenai fotografi dan gaya busana. Untuk menganalisisnya hanya akan menggunakan beberapa elemen dari setiap unsur teori sesuai dengan keperluan dalam membedah foto. Setiap kategori foto dari masing-masing instagram merek lokal hijab tersebut akan diambil 5-10 foto sebagai pembanding satu sama lainnya. Sampel foto yang diambil berdasarkan likes terbanyak minimal 50 likes. Berikut penjabaran setiap kategori dari ketiga merek lokal hijab di Bandung.

Tabel 2.1 Rangkuman analisis visual kategori foto produk (single)

\begin{tabular}{|c|c|c|c|c|c|c|c|}
\hline $\begin{array}{c}\text { Merek } \\
\text { Hijab }\end{array}$ & $\begin{array}{c}\text { Tonal } \\
\text { Warna }\end{array}$ & $\begin{array}{l}\text { Shot } \\
\text { Type }\end{array}$ & $\begin{array}{c}\text { Objek } \\
\text { Foto }\end{array}$ & Latar & Komposisi & Aksesoris & $\begin{array}{l}\text { Atribut } \\
\text { Busana }\end{array}$ \\
\hline $\begin{array}{l}\text { Juniper } \\
\text { Lane }\end{array}$ & $\begin{array}{l}\text { Keabu- } \\
\text { abuan }\end{array}$ & $\begin{array}{l}\text { Wide } \\
\text { shot dan } \\
\text { medium } \\
\text { shot }\end{array}$ & $\begin{array}{c}\text { Model } \\
\text { wanita } \\
\text { asing }\end{array}$ & Outdoor & $\begin{array}{l}\text { Seimbang } \\
\text { dan Rule of } \\
\text { third }\end{array}$ & $\begin{array}{l}\text { Jilbab: scarf, } \\
\text { pashmina, \& } \\
\text { turban. } \\
\text { Sepatu: } \\
\text { high heels } \\
\text { \& platform } \\
\text { sandals. } \\
\text { Perhiasan: } \\
\text { kalung \& } \\
\text { anting-anting. }\end{array}$ & $\begin{array}{c}\text { Pakaian } \\
\text { atasan, } \\
\text { tunik, } \\
\text { outer } \\
\text { wear } \\
\text { dan } \\
\text { dress }\end{array}$ \\
\hline Zaha & $\begin{array}{l}\text { Keabu- } \\
\text { abuan }\end{array}$ & $\begin{array}{l}\text { Medium } \\
\text { shot }\end{array}$ & $\begin{array}{c}\text { Model } \\
\text { wanita } \\
\text { asing }\end{array}$ & Indoor & Seimbang & $\begin{array}{l}\text { Jilbab: } \\
\text { pashmina } \\
\text { Sepatu: high } \\
\text { heels. } \\
\text { Perhiasan: } \\
\text { kalung. }\end{array}$ & Tunik \\
\hline $\begin{array}{l}\text { Zysku } \\
\text { Xena }\end{array}$ & $\begin{array}{l}\text { Keabu- } \\
\text { abuan }\end{array}$ & $\begin{array}{l}\text { Wide } \\
\text { shot }\end{array}$ & $\begin{array}{c}\text { Model } \\
\text { wanita } \\
\text { asing }\end{array}$ & Indoor & Seimbang & $\begin{array}{l}\text { Jilbab: } \\
\text { pashmina } \\
\text { Sepatu: high } \\
\text { heels. }\end{array}$ & $\begin{array}{c}\text { Dress, } \\
\text { tunik } \\
\text { dan } \\
\text { celana } \\
\text { panjang }\end{array}$ \\
\hline
\end{tabular}

Dari tabel di atas dapat dijabarkan bahwa foto dengan kategori produk (single), kecenderungan dari ketiga merek lokal hijab ini memiliki tonal warna keabu-abuan pada foto produknya. Warna keabu-abuan menurut Eiseman ${ }^{14}$ dapat memberikan kesan profesional, berkualitas, dan terlihat mahal. Jenis pengambilan gambar pada foto yang lebih banyak disukai oleh konsumen pada ketiga merek ini berbeda-beda. Untuk Juniper Lane, jenis pengambilan gambar dengan tipe wide shot dan medium shot hampir seimbang disukai. Sedangkan

${ }^{14}$ Leatrice Eiseman, Pantone Guide to Communicating with Color, (Florida: Grafix Press, Ltd, 2000), h. 63 
dari label Zaha, jenis pengambilan gambar yang lebih banyak mendapatkan likes adalah tipe medium shot. Jenis pengambilan gambar yang dipakai oleh merek hijab Zysku Xena semuanya hampir menggunakan tipe wide shot. Untuk kategori objek, model wanita dengan paras asing lebih banyak mendapatkan likes ketimbang model dengan paras lokal. Pada background foto, konsumen memiliki perbedaan penilaian untuk ketiga label ini. Foto dari Juniper Lane lebih banyak disukai dengan latar outdoor. Foto merek Zaha dan Zysku Xena lebih banyak menggunakan background indoor di dalam ruangan. Begitupun dengan komposisi yang digunakan dalam pengambilan foto. Merek Juniper Lane karena banyak menggunakan latar outdoor maka komposisinya lebih bervariasi antara komposisi seimbang dan rule of third. Sedangkan untuk Zaha dan Zysku Xena kecenderungan menggunakan komposisi seimbang.

Untuk jenis busana dan aksesori yang mendapatkan likes terbanyak juga bervariasi antar ketiga label ini. Busana yang disukai pada merek Juniper Lane hampir seimbang antar satu sama lainnya, seperti pakaian atasan, tunik, outer, dan dress. Aksesori yang dikenakan pada model juga beragam kreasi seperti penggunaan jilbab yang bervariasi mulai dari scarf, pashmina, dan turban; model sepatu seperti high heels dan platform sandals; serta jenis perhiasan seperti kalung, antinganting, dan headband. Sedangkan merek Zaha lebih banyak disukai busana dengan jenis tunik. Aksesori pelengkap yang banyak digunakan adalah pashmina, perhiasan kalung, dan high heels. Untuk foto busana dari Zysku Xena yang mendapatkan likes terbanyak adalah jenis dress dan tunik yang dipadukan dengan celana panjang. Aksesori yang dikenakan pada model sangat simpel sebatas penggunaan pashmina dan high heels saja.

Tabel 2.2 Rangkuman analisis visual kategori foto produk (gabungan)

\begin{tabular}{|c|c|c|c|c|c|c|c|c|}
\hline $\begin{array}{l}\text { Merek } \\
\text { Hijab }\end{array}$ & $\begin{array}{l}\text { Tonal } \\
\text { Warna }\end{array}$ & $\begin{array}{l}\text { Shot } \\
\text { Type }\end{array}$ & $\begin{array}{c}\text { Arah } \\
\text { Pandang } \\
\text { Kamera }\end{array}$ & $\begin{array}{l}\text { Objek } \\
\text { Foto }\end{array}$ & Latar & $\begin{array}{c}\text { Kompo- } \\
\text { sisi }\end{array}$ & Aksesoris & $\begin{array}{l}\text { Atribut } \\
\text { Busana }\end{array}$ \\
\hline $\begin{array}{l}\text { Juniper } \\
\text { Lane }\end{array}$ & $\begin{array}{l}\text { Keabu- } \\
\text { abuan }\end{array}$ & $\begin{array}{l}\text { Wide } \\
\text { shot }\end{array}$ & $\begin{array}{c}\text { Depan, } \\
\text { samping } \\
\text { dan } \\
\text { belakang }\end{array}$ & $\begin{array}{c}\text { Model } \\
\text { wanita } \\
\text { asing }\end{array}$ & Indoor & Seimbang & $\begin{array}{l}\text { Pashmina } \\
\text { dan high } \\
\text { heels/ } \\
\text { platform } \\
\text { sandals }\end{array}$ & $\begin{array}{c}\text { Tunik } \\
\text { dan } \\
\text { celana } \\
\text { panjang }\end{array}$ \\
\hline Zaha & $\begin{array}{l}\text { Keabu- } \\
\text { abuan }\end{array}$ & $\begin{array}{l}\text { Wide } \\
\text { shot, } \\
\text { medium } \\
\text { shot, } \\
\text { dan } \\
\text { close up }\end{array}$ & $\begin{array}{c}\text { Depan, } \\
\text { samping } \\
\text { dan } \\
\text { belakang }\end{array}$ & $\begin{array}{c}\text { Model } \\
\text { wanita } \\
\text { asing }\end{array}$ & Indoor & Seimbang & $\begin{array}{l}\text { Pashmina } \\
\text { dan high } \\
\text { heels/ } \\
\text { platform } \\
\text { sandals }\end{array}$ & $\begin{array}{c}\text { Dress, } \\
\text { outer } \\
\text { wear, } \\
\text { dan } \\
\text { pakaian } \\
\text { atasan }\end{array}$ \\
\hline
\end{tabular}

\begin{tabular}{|c|c|c|c|c|c|c|c|c|}
\hline $\begin{array}{l}\text { Zysku } \\
\text { Xena }\end{array}$ & $\begin{array}{l}\text { Keabu- } \\
\text { abuan }\end{array}$ & $\begin{array}{l}\text { Wide } \\
\text { shot, } \\
\text { medium } \\
\text { shot, } \\
\text { dan } \\
\text { close } \\
\text { up }\end{array}$ & $\begin{array}{c}\text { Depan, } \\
\text { samping } \\
\text { dan } \\
\text { belakang }\end{array}$ & $\begin{array}{c}\text { Model } \\
\text { wanita } \\
\text { asing }\end{array}$ & Indoor & Seimbang & $\begin{array}{l}\text { Pashmina } \\
\text { dan high } \\
\text { heels/ } \\
\text { platform } \\
\text { sandals }\end{array}$ & $\begin{array}{c}\text { Tunik, } \\
\text { outer } \\
\text { wear } \\
\text { dan } \\
\text { celana } \\
\text { panjang }\end{array}$ \\
\hline
\end{tabular}

Pada tabel foto produk (gabungan) di atas, tonal warna yang digunakan oleh ketiga merek hijab ini rata-rata adalah keabu-abuan. Penggunaan jenis pengambilan gambar pada kategori ini cukup berbeda-beda setiap merek hijab. Untuk Juniper Lane, jenis pengambilan gambar yang digunakan rata-rata hanya jenis wide shot saja. Sedangkan label Zaha, memakai jenis pengambilan gambar sesuai dengan produk yang sedang ditawarkan, seperti wide shot untuk dress, medium shot untuk pakian atasan, dan close up untuk memfokuskan kedetail bagian pakaian tertentu. Jenis pengambilan gambar yang digunakan Zysku Xena hampir disemua foto produk (gabungan) memakai tipe wide shot, medium shot, dan close up. Untuk arah pandang kamera, foto kategori ini cenderung memperlihatkan sudut tampak depan, samping, dan belakang agar penampakan busana terlihat dengan jelas. Penggunaan model yang mendapatkan banyak likes pada foto produk (gabungan) yaitu model wanita berparas asing. Ketiga merek lokal hijab ini banyak menggunakan komposisi seimbang. Untuk jenis aksesori pelengkap busana yang dikenakan kepada model, ketiga label ini cukup simpel sebatas pashmina dan platform sandals atau high heels. Atribut busana untuk kategori foto produk (gabungan) yang banyak disukai konsumen setiap brand memiliki hasil yang berbeda. Juniper Lane cenderung lebih disukai busana jenis tunik dan celana panjang, Zaha dengan busana jenis dress, outer, dan pakaian atasan, sedangkan Zysku Xena lebih kepada busana jenis tunik dan outer yang dipadukan dengan celana panjang.

Tabel 2.3 Rangkuman analisis visual kategori foto produk dipakai selebriti/selebgram

\begin{tabular}{ccccccc}
\hline $\begin{array}{c}\text { Merek } \\
\text { Hijab }\end{array}$ & Tonal Warna & Shot Type & Latar & Komposisi & Aksesoris & $\begin{array}{c}\text { Atribut } \\
\text { Busana }\end{array}$ \\
\hline $\begin{array}{c}\text { Juniper } \\
\text { Lane }\end{array}$ & Berbeda- \\
beda: warna- & Wide shot & Outdoor & Seimbang & Jilbab: & Tunik \\
& scarf \& & dan \\
& warna cerah. & & & pashmina & celana \\
& Pantone & & & Sepatu, & panjang \\
& nuansa: & & & kacamata, & skinny \\
& muted dan & & & tas tangan, & \\
& capricious. & & & jam tangan \\
\hline
\end{tabular}




\begin{tabular}{|c|c|c|c|c|c|c|}
\hline Zaha & $\begin{array}{c}\text { Berbeda- } \\
\text { beda: warna- } \\
\text { warna cerah. } \\
\text { Pantone } \\
\text { nuansa: } \\
\text { muted dan } \\
\text { capricious }\end{array}$ & Wide shot & Outdoor & $\begin{array}{c}\text { Rule of } \\
\text { third }\end{array}$ & $\begin{array}{c}\text { Jilbab: } \\
\text { scarf \& } \\
\text { pashmina } \\
\text { Sepatu: } \\
\text { high heels } \\
\text { Kacamata, } \\
\text { tas tangan, } \\
\text { jam tangan }\end{array}$ & $\begin{array}{c}\text { Dress, } \\
\text { pakaian } \\
\text { atasan } \\
\text { dan } \\
\text { celana } \\
\text { panjang }\end{array}$ \\
\hline $\begin{array}{c}\text { Zysku } \\
\text { Xena }\end{array}$ & $\begin{array}{c}\text { Berbeda- } \\
\text { beda: warna- } \\
\text { warna cerah. } \\
\text { Pantone } \\
\text { nuansa: } \\
\text { muted dan } \\
\text { capricious }\end{array}$ & Wide shot & Outdoor & Seimbang & $\begin{array}{l}\text { Jilbab: } \\
\text { scarf \& } \\
\text { pashmina } \\
\text { Sepatu: } \\
\text { high heels } \\
\text { \& platform } \\
\text { sandals } \\
\text { Kacamata, } \\
\text { tas tangan, } \\
\text { jam tangan }\end{array}$ & $\begin{array}{c}\text { Tunik } \\
\text { dan } \\
\text { celana } \\
\text { panjang } \\
\text { skinny }\end{array}$ \\
\hline
\end{tabular}

Berdasarkan tabel di atas, foto yang dihadirkan untuk kategori produk yang dipakai selebriti/selebgram memiliki tonal warna yang berbeda-beda setiap fotonya. Kebanyakan foto dari para selebriti/selebgram yang lebih disukai oleh followers adalah foto dengan warna-warna cerah. Jika dilihat kombinasi antar pantone yang dihasilkan oleh foto kategori ini, berdasarkan Eiseman ${ }^{15}$ dan Dameria $^{16}$ warna yang tercipta membentuk nuansa muted dan capricious. Kedua nuansa warna ini memberikan kesan alami dan sederhana. Untuk jenis pengambilan gambar yang digunakan oleh para selebriti/selebgram ini kecenderungan memakai teknik wide shot. Pengambilan komposisi foto yang banyak mendapatkan likes, untuk Juniper Lane dan Zysku Xena adalah komposisi seimbang, sedangkan Zaha banyak yang menyukai foto dengan komposisi rule of third. Setiap merek hijab ini, jenis busana yang mendapatkan perhatian konsumen berbeda-beda. Juniper Lane dan Zysku Xena banyak disukai dengan atribut busana jenis tunik yang dipadukan dengan legging atau celana panjang skinny/jogger. Sedangkan Zaha lebih disukai dengan selebriti/ selebgram yang memakai busana jenis satu set pakaian seperti atasan dan celana, dan dress. Untuk aksesori yang dikenakan oleh para selebriti/selebgram cukup beragam. Jika foto untuk kategori produk menggunakan aksesori yang simpel, para selebriti/selebgram ini cenderung banyak menambahkan aksesori seperti kacamata, tas tangan, jam tangan dan berbagai macam jenis sepatu.

${ }^{15}$ Leatrice Eiseman, Pantone Guide to Communicating with Color, (Florida: Grafix Press, Ltd, 2000), h. 72-75.

${ }^{16}$ Anne Dameria, Color Basic, Panduan Dasar Warna untuk Desainer dan Industri, (Jakarta: Link \& Match Graphic, 2007), h. lampiran 1.1: VII \& VIII.
Tabel 2.4 Rangkuman analisis visual kategori foto konsumen memakai produk

\begin{tabular}{|c|c|c|c|c|c|c|}
\hline $\begin{array}{c}\text { Merek } \\
\text { Hijab }\end{array}$ & Tonal Warna & $\begin{array}{l}\text { Shot } \\
\text { Type }\end{array}$ & Latar & Komposisi & Aksesoris & $\begin{array}{l}\text { Atribut } \\
\text { Busana }\end{array}$ \\
\hline $\begin{array}{l}\text { Juniper } \\
\text { Lane }\end{array}$ & $\begin{array}{l}\text { Berbeda-beda: } \\
\text { warna-warna } \\
\text { cerah. } \\
\text { Pantone nuansa: } \\
\text { muted dan } \\
\text { capricious }\end{array}$ & $\begin{array}{l}\text { Wide } \\
\text { shot }\end{array}$ & Outdoor & Seimbang & $\begin{array}{l}\text { Jilbab: } \\
\text { scarf \& } \\
\text { pashmina } \\
\text { Sepatu, } \\
\text { tas, } \\
\text { perhiasan }\end{array}$ & $\begin{array}{c}\text { Tunik, dress, } \\
\text { outer wear, } \\
\text { dan pakaian } \\
\text { atasan }\end{array}$ \\
\hline Zaha & $\begin{array}{l}\text { Berbeda-beda: } \\
\text { warna-warna } \\
\text { cerah. } \\
\text { Pantone nuansa: } \\
\text { muted dan } \\
\text { capricious }\end{array}$ & $\begin{array}{l}\text { Wide } \\
\text { shot }\end{array}$ & Indoor & Seimbang & $\begin{array}{l}\text { Jilbab: } \\
\text { scarf \& } \\
\text { pashmina } \\
\text { Sepatu, } \\
\text { tas, } \\
\text { perhiasan }\end{array}$ & $\begin{array}{c}\text { Pakaian } \\
\text { atasan, tunik } \\
\text { dan legging }\end{array}$ \\
\hline $\begin{array}{c}\text { Zysku } \\
\text { Xena }\end{array}$ & $\begin{array}{c}\text { Berbeda-beda: } \\
\text { warna-warna } \\
\text { cerah. } \\
\text { Pantone nuansa: } \\
\text { muted dan } \\
\text { capricious }\end{array}$ & $\begin{array}{l}\text { Wide } \\
\text { shot }\end{array}$ & Outdoor & Seimbang & $\begin{array}{l}\text { Jilbab: } \\
\text { scarf \& } \\
\text { pashmina } \\
\text { Sepatu, } \\
\text { tas, } \\
\text { perhiasan }\end{array}$ & $\begin{array}{l}\text { Tunik dan } \\
\text { celana } \\
\text { panjang }\end{array}$ \\
\hline
\end{tabular}

Dari tabel di atas menunjukkan kesamaan dengan kategori produk yang dipakai selebriti/ selebgram, foto konsumen ini juga memberikan tonal warna yang bervariasi. Kebanyakan foto para konsumen tersebut bernuansa cerah dan terang. Nuansa dari pantone yang diciptakan oleh kategori ini juga sama dengan kategori produk dipakai selebriti/selebgram yaitu nuansa muted dan capricious. Kedua nuansa warna ini memberikan kesan alami dan sederhana ${ }^{17}$. Ketiga merek hijab mengambil foto dengan jenis pengambilan gambar wide shot dan menggunakan komposisi seimbang. Untuk latar foto yang lebih banyak disukai followers instagram berbeda-beda. Foto konsumen yang memakai produk Zaha lebih banyak mendapatkan likes dengan background indoor, sedangkan Zaha dan Zysku Xena lebih disukai yang menggunakan latar outdoor. Untuk aksesori yang dipakai oleh para konsumen dari ketiga merek hijab ini cukup bervariasi jika dibandingkan dengan kategori sebelumnya. Aksesori yang banyak dikenakan seperti berbagai macam jenis tas, scarf, perhiasan, dan sepatu. Jenis atribut busana yang banyak disukai konsumenpun cukup beda antar merek. Juniper Lane banyak mendapatkan likes hampir semua jenis busana yang dimiliki label ini yaitu tunik, outer, pakaian atasan, dan dress. Sedangkan Zaha jenis pakaian yang disukai adalah atasan, tunik yang dipadukan dengan legging. Merek Zysku Xena banyak disukai hanya jenis busana tunik yang dipadukan dengan celana panjang.

${ }^{17}$ Leatrice Eiseman, Pantone Guide to Communicating with Color, (Florida: Grafix Press, Ltd, 2000), h. 72-75. 
Tabel 2.5 Rangkuman analisis visual kategori foto kegiatan penjualan offline

\begin{tabular}{|c|c|c|c|c|}
\hline $\begin{array}{c}\text { Merek } \\
\text { Hijab }\end{array}$ & Tonal Warna & $\begin{array}{l}\text { Shot } \\
\text { Type }\end{array}$ & Objek Foto & Komposisi \\
\hline $\begin{array}{l}\text { Juniper } \\
\text { Lane }\end{array}$ & $\begin{array}{l}\text { Berbeda-beda } \\
\text { tergantung suasana } \\
\text { dan tempat terjadi. } \\
\text { Pantone nuansa: } \\
\text { classic dan natural }\end{array}$ & $\begin{array}{l}\text { Wide } \\
\text { shot }\end{array}$ & $\begin{array}{l}\text { Konsumen yang } \\
\text { sedang memilih } \\
\text { produk dan } \\
\text { produk pakaian } \\
\text { yang dipajang }\end{array}$ & $\begin{array}{c}\text { Rule of } \\
\text { third }\end{array}$ \\
\hline Zaha & $\begin{array}{l}\text { Berbeda-beda } \\
\text { tergantung suasana } \\
\text { dan tempat terjadi. } \\
\text { Pantone nuansa: } \\
\text { classic dan natural }\end{array}$ & $\begin{array}{l}\text { Wide } \\
\text { shot }\end{array}$ & $\begin{array}{l}\text { Konsumen yang } \\
\text { sedang memilih } \\
\text { produk dan } \\
\text { produk pakaian } \\
\text { yang dipajang }\end{array}$ & $\begin{array}{l}\text { Rule of } \\
\text { third }\end{array}$ \\
\hline $\begin{array}{c}\text { Zysku } \\
\text { Xena }\end{array}$ & $\begin{array}{l}\text { Berbeda-beda } \\
\text { tergantung suasana } \\
\text { dan tempat terjadi. } \\
\text { Pantone nuansa: } \\
\text { classic dan natural }\end{array}$ & $\begin{array}{l}\text { Wide } \\
\text { shot }\end{array}$ & $\begin{array}{l}\text { Konsumen yang } \\
\text { sedang memilih } \\
\text { produk dan } \\
\text { produk pakaian } \\
\text { yang dipajang }\end{array}$ & $\begin{array}{l}\text { Rule of } \\
\text { third }\end{array}$ \\
\hline
\end{tabular}

Tabel di atas memaparkan merek Juniper Lane, Zaha, dan Zysku Xena ini hampir memiliki kesamaan untuk kategori kegiatan penjualan offline. Foto yang lebih banyak disukai oleh konsumen adalah foto seperti suasana konsumen yang sedang memilih dan berbelanja produk, penampakan dari toko fisik yang dimiliki, serta produk-produk yang sedang dipajang. Jenis pengambilan gambar pada foto rata-rata adalah tipe wide shot karena dapat memperlihatkan suasana yang sedang berlangsung. Untuk komposisipun juga memiliki kesamaan antar ketiga merek ini yaitu samasama menggunakan komposisi rule of third. Tonal warna yang tertangkap kamera dari ketiga label hijab ini bervariasi antar foto satu sama lainnya. Kecenderungan foto memberikan tonal warna-warna bersifat real-time yaitu tergantung dengan suasana dari tempat terjadinya kegiatan berlangsung. Jika dilihat kombinasi antar pantone yang dihasilkan oleh foto kategori ini, warna yang tercipta membentuk nuansa classic dan natural. Kedua nuansa warna ini memberikan kesan kesederhanaan, otentik, dan netral ${ }^{18}$.

Tabel 2.6 Rangkuman analisis visual kategori foto kegiatan di luar penjualan (fashion show)

\begin{tabular}{cccc}
\hline $\begin{array}{c}\text { Merek } \\
\text { Hijab }\end{array}$ & Tonal Warna & Shot Type & Komposisi \\
\hline $\begin{array}{c}\text { Juniper } \\
\text { Lane }\end{array}$ & $\begin{array}{c}\text { Biru dan violet. } \\
\text { Pantone nuansa: } \\
\text { spiritual dan serene }\end{array}$ & $\begin{array}{c}\text { Wide } \\
\text { shot dan } \\
\text { medium } \\
\text { shot }\end{array}$ & Rule of third \\
& & \\
\hline
\end{tabular}

${ }^{18}$ Leatrice Eiseman, Pantone Guide to Communicating with Color, (Florida: Grafix Press, Ltd, 2000), h. $96 \& 118$

\begin{tabular}{cccc}
\hline Zaha & $\begin{array}{c}\text { Kebiru-biruan. } \\
\text { Pantone nuansa: } \\
\text { spiritual dan serene }\end{array}$ & Wide shot & Seimbang \\
\hline $\begin{array}{c}\text { Zysku } \\
\text { Xena }\end{array}$ & $\begin{array}{c}\text { Kekuning-kuningan. } \\
\text { Pantone nuansa: } \\
\text { spiritual dan serene }\end{array}$ & $\begin{array}{c}\text { Medium } \\
\text { shot }\end{array}$ & Seimbang \\
\hline
\end{tabular}

Berdasarkan tabel di atas, untuk foto kategori kegiatan di luar penjualan ini memiliki variasi dalam tonal warna. Setiap foto tergantung dari pencahayaan pada saat berlangsungnya fashion show, seperti Juniper Lane lebih banyak foto dengan nuansa warna biru dan violet, Zaha menghadirkan warna kebiru-biruan, dan Zysku Xena lebih banyak warna kekuning-kuningan. Meski demikian, kombinasi antar pantone yang dihasilkan oleh foto kategori ini, berdasarkan Eiseman ${ }^{19}$ dan Dameria ${ }^{20}$ warna yang tercipta membentuk nuansa spiritual dan serene. Kedua nuansa warna ini memberikan kesan mempesona, misterius, dan menenangkan. Jenis pengambilan gambar dalam foto yang banyak digunakan untuk brand Zaha dan Zysku Xena lebih banyak mengambil secara wide shot dan menggunakan komposisi seimbang, sehingga kegiatan fashion show yang sedang berlangsung dapat terlihat dengan jelas. Sedangkan Juniper Lane menggunakan jenis pengambilan gambar antara wide shot dan medium shot sama banyaknya. Jenis pengambilan gambar wide shot dapat menghadirkan suasana kegiatan yang sedang terjadi dan medium shot lebih memfokuskan ke detail dari produk yang dipamerkan. Untuk komposisi pada Juniper Lane banyak menggunakan jenis rule of third.

\section{Persepsi Konsumen Terhadap Elemen Visual pada Promosi Instagram Merek Juniper Lane, Zaha, dan Zysku Xena}

Pada penelitian ini telah dilakukan wawancara kepada 30 orang wanita muslimah yang merupakan konsumen dari merek lokal hijab di Bandung dan pengguna aktif instagram. Konsumen tersebut umumnya mempunyai persepsi tersendiri terhadap foto busana muslimah pada instagram ketiga merek hijab di Bandung. Persepsi konsumen

${ }^{19}$ Leatrice Eiseman, Pantone Guide to Communicating with Color, (Florida: Grafix Press, Ltd, 2000), h. 66 \& 76.

${ }^{20}$ Anne Dameria, Color Basic, Panduan Dasar Warna untuk Desainer dan Industri, (Jakarta: Link \& Match Graphic, 2007), h. lampiran 1.1: IV \& IX. 
terhadap promosi instragram merek lokal hijab di Bandung amat tergantung pada elemen visual dan gaya busana yang dilihatnya. Secara umum konsumen cenderung memberi persepsi yang berbeda pada setiap elemen visual fotografi. Namun secara keseluruhan elemen visual dan gaya busana tersebut telah memberikan kontribusi yang positif terhadap rencana konsumen untuk membeli produk merek lokal hijab di Bandung. Hal ini berarti bahwa elemen visual dan gaya busana pada promosi Intragram terbukti dapat meningkatkan tiras penjualan. Beberapa bukti bahwa elemen visual fotografi dan gaya busana pada promosi instagram dapat meningkatkan penjualan sebagai berikut.

Pertama, konsumen mempunyai persepsi yang positif terhadap foto instagram merek hijab lokal di Bandung dilihat dari tonal warna. Persepsi terhadap foto instagram kategori single dan gabungan cenderung ke arah professional, berkualitas, dan terlihat mahal. Persepsi terhadap foto instagram kategori selebriti/selebgram dan konsumen memakai produk cenderung ke arah alami dan sederhana. Persepsi terhadap foto kegiatan penjualan offline cenderung ke arah sederhana, otentik, dan netral. Persepsi terhadap foto pada kategori kegiatan diluar penjualan (fashion show) cenderung ke arah mempesona, misterius, dan menenangkan. Beberapa persepsi yang positif ini menurut konsumen dapat menimbulkan keinginan untuk membeli produk hijab tersebut.

Kedua, persepsi konsumen terhadap foto promosi instagram pada merek lokal hijab di Bandung dilihat dari jenis pengambilan gambar cenderung kearah medium shot (gambaran sedang), wide shot (gambaran menyeluruh) dan close up (gambaran detail).

Ketiga, persepsi konsumen terhadap foto produk cenderung menyukai arah pandang kamera yang tampak depan, samping, dan belakang. Hal itu karena arah pandang kamera dapat memberikan gambaran produk yang dapat dilihat dari berbagai sisi secara keseluruhan.

Keempat, konsumen mempunyai persepsi positif terhadap elemen objek foto instagram cenderung menyukai model wanita asing. Hal ini karena wanita asing lebih cantik, berkulit putih, dan bentuk tubuh yang proporsional, sehingga membuat tampilan foto terlihat lebih professional.

Kelima, konsumen mempunyai persepsi terhadap foto instagram ketiga merek lokal hijab dilihat dari elemen latar cenderung berbeda pandangannya. Konsumen lebih menyukai penggunaan background indoor untuk foto produk dan outdoor untuk kategori foto selain produk. Perbedaan ini amat tergantung dari kejelasan obyek foto yang dipromosikan.

Keenam, persepsi konsumen terhadap elemen visual komposisi pada tampilan foto instagram ketiga merek hijab kecenderungan berbeda pendapat tergantung objek fotonya. Untuk kategori foto single dan gabungan, serta foto selebriti/selebgram dan konsumen memakai produk lebih menyukai foto dengan komposisi seimbang. Sedangkan untuk kategori kegiatan penjualan offline dan fashion show cenderung lebih menyukai komposisi rule of third.

Ketujuh, persepsi konsumen terhadap pemakaian busana yang dipadukan dengan aksesori lebih banyak disukai. Hal ini dapat membuat tampilan busana lebih terlihat menarik ketimbang produk busana yang tidak memakai aksesori.

Kedelapan, konsumen umumnya memberikan persepsi terhadap elemen atribut jenis busana pada foto instagram promosi merek hijab lokal di Bandung dengan gaya busana yang lengkap. Busana yang lebih disukai yakni pakaian atasan, tunik, outer wear, dress, dan celana panjang. Hal itu karena terlihat lebih lengkap dan menutupi seluruh badan, lebih modis, dan mengikuti tren sesuai dengan perkembangan mode di era sekarang.

Berdasarkan padangan konsumen tersebut menunjukkan bahwa owner (pemilik) merek dagang busana muslimah belum sepenuhnya memenuhi etika perdagangan Islam, seperti etika teistis (rabbaniyyah) yang sesuai dengan ketentuan Allah Swt dan etis (akhlaqiyyah) yang bermoral baik ${ }^{21}$. Pemilik merek semata-mata hanya memenuhi kebutuhan konsumen dan kurang sepenuhnya mematuhi etika dan nilai-nilai Islam, seperti pemilihan warna yang berwarna-warni,

${ }^{21}$ Muhammad Sula dan Hermawan Kartajaya, Syariah Marketing, (Jakarta: Mizan, 2005), h. 28-39 
busana yang kurang longgar (ketat), dan aksesori yang kurang sesuai dengan syariah Islam.

\section{Penutup}

Elemen visual fotografi busana muslimah pada Instagram terbukti dapat meningkatkan promosi pemasaran produk. Hal ini memberikan indikasi bahwa ketiga merek dagang busana muslimah yang dipromosikan secara online yang memenuhi etika perdagangan Islam seperti sesuai dengan syariah Islam, bermoral baik, profesional, dan menjunjung tinggi nilai kemanusiaan; mampu memberikan dampak terhadap peningkatan pemasaran produk.

Secara khusus elemen visual fotografi yang meningkatkan pemasaran dan sesuai dengan etika perdagangan Islam, yaitu (1) penggunaan tonal warna yang kebanyakan keabu-abuan dapat memberikan persepsi profesional, berkualitas, dan terlihat mahal pada produk, (2) penggunaan elemen jenis pengambilan gambar yang wide shot dapat memberikan gambaran keseluruhan produk, medium shot memberikan gambaran lebih terfokus, dan close up memberikan gambaran produk yang lebih rinci, (3) penggunaan elemen arah pandang kamera yang tampak depan, samping dan belakang, dapat memberikan gambaran produk dari berbagai sisi, (4) penggunaan elemen objek foto yang menggunakan model asing, lebih memberikan tampilan internasional dan tampak indah ketika difoto, (5) penggunaan elemen latar dengan background indoor dapat membuat produk nampak lebih fokus dan jelas, (6) penggunaan elemen komposisi yang seimbang, dapat memberikan tampilan produk lebih menonjol, tidak terpotong, dan konsumen menjadi lebih terfokus, (7) penggunaan busana yang dipadukan dengan aksesori, dapat memberikan dampak kepada foto produk lebih disukai, dan (8) jenis atribut busana seperti pakaian atasan, tunik, outer wear, dress dan celana panjang merupakan busana paling banyak disukai konsumen.

Disamping itu, konsumen cenderung memberi persepsi bahwa elemen visual dan gaya busana dapat memberikan kontribusi yang positif terhadap rencana membeli produk merek lokal hijab di Bandung. Hal ini berarti bahwa strategi pemasaran melalui instagram yang memenuhi elemen visual fotografi terbukti dapat meningkatkan penjualan produk.

Foto busana muslimah yang ditampilkan pada ketiga merek lokal hijab di Bandung ini memang kurang sesuai dengan kriteria berbusana yang ditetapkan Majelis Ulama Indonesia (MUI), seperti pakaian yang berwarna-warni dan bentuk pakaian kurang longgar. Kondisi ini juga menunjukan bahwa pemilik merek dagang busana muslimah belum mampu memenuhi etika yang sesuai syariah dan bermoral baik. Walaupun demikian, antusias wanita muslimah dalam memakai hijab yang dibalut dengang fashion ini dapat menjadi batu pijakan agar para wanita menutupi auratnya. Selain hal tersebut, kehadiran antusias wanita pada hijab dapat memberikan harapan bagi Indonesia untuk menjadi kiblat fashion dunia sehingga memberikan manfaat yang besar untuk negara ini.

\section{Pustaka Acuan}

Covey, Stephen R, The 7 Habits of Highly Effective People, Jakarta: Binarupa Aksara, 1997.

Dameria, Anne, Color Basic, Panduan Dasar Warna untuk Desainer dan Industri, Jakarta: Link \& Match Graphic, 2007.

Eiseman, Leatrice, Pantone Guide to Communicating with Color, Florida: Grafix Press, Ltd, 2000.

Jawa Pos, Andalkan Distinctive Style, Digandrungi Pasar Australia. http://beta.tirto.id/20160314media-cetak/andalkan-distinctive-styledigandrungi-pasar-australia-55167/, diakses tanggal 27 Mei 2016.

Kusuma, Fifi, Hijab dan Perempuan Indonesia. http://www.kompasiana.com/fifikusuma/ hijab-dan-perempuan-indonesia_54f681bfa 3331184118 b4dd2, diakses tanggal 23 Februari 2016).

Larasati, Agnessia P, Hijab Syari vs Hijab Gaul, Fenomena Hijab Masa Kini. https://www. muslimarket.com/blog/hijab-syari-vs-hijabgaul-fenomena-hijab-masa-kini/, diakses tanggal 30 Mei 2016.

Martin, B. dan Hanington, B, Universal Methods of Design: 100 Ways to Research Complex Problems, Develop Innovative Ideas, and Design Effective Solutions, Beverly: Rockport Publishers, 2012. 
Parakkasi, Idris, Marketing Syariah, http:// konsultanekonomi.blogspot.co.id/2012/05/ marketing-syariah.html, diakses tanggal 22 Mei 2017.

Smart Bisnis, Peran Design Visual dalam Pemasaran Produk. http://www.smartbisnis.co.id/content/ read/belajar-bisnis/inisiasi-bisnis/peran-designvisual-dalam-pemasaran-produk, diakses tanggal 16 September 2016.

Soewardikoen, Didit Widiatmoko, Metodologi Penelitian Visual dari Seminar ke Tugas Akhir, Bandung: CV Dinamika Komunika, 2013.
Sugiyono, Memahami Penelitian Kualitatif, Bandung: Alfabeta, 2012.

Sukendro, Gatot, Nilai Fetisisme Komoditi Gaya Hijab (Kerudung dan Jilbab) dalam Busana Muslimah, Bandung: Tesis S2 Prodi Desain, 2015.

Sula, Muhammad dan Hermawan Kartajaya, Syariah Marketing, Jakarta: Mizan, 2005.

Supriadi, Cecep, Pasar Muslim Indonesia yang Menggiurkan. http://www.marketing.co.id/ pasar-muslim-indonesia-yang-menggiurkan/, diakses tanggal 23 Februari 2016. 